\title{
Protection of minors: lessons about the FIFA RSTP from the recent Spanish cases at the Court of Arbitration for Sport
}

\author{
Serhat Yilmaz ${ }^{1}$ (D) \\ Published online: 25 April 2018 \\ (C) The Author(s) 2018
}

\begin{abstract}
The publication of recent CAS awards concerning minors in Spanish football involving two football giants, Fútbol Club Barcelona and Real Madrid Club de Fútbol, and the national association, The Real Federació Española de Fútbol, offers a valuable opportunity to analyse the operation of the regulatory regime for the protection of minors under FIFA's Regulations on the Status and Transfer of Players (RSTP). By synthesising legal reasoning used by the CAS Panels and the Sole Arbitrator in three cases, this article presents a holistic view of the regulatory framework for minors established by FIFA which extends beyond Art. 19 of the RSTP and then highlights some important lessons for its operation in practice. The liability of national associations concerning minors, the applicability of the regulatory framework to all minors, and the distinction between the registration requirements of minors in participating in organised football and reporting requirements in relation with minors in academies are all discussed and explained. This paper represents a contribution into a limited literature with regard to both the regulation of minors in football and the analysis of CAS jurisprudence on the topic.
\end{abstract}

Keywords Registration of minors - International transfer certificate · FIFA · Transfer matching system - Sports law

\section{Introduction}

Over the course of last two decades, a growing appetite for cheap, promising young talents in football, led to an increase in the numbers of minors moving away from their home to pursue a footballing career. ${ }^{1}$ A record number of 2323 minors were registered with clubs worldwide in $2015^{2}$ and applications for the registration of young players made to the Fédération Internationale de Football Association (FIFA) reached a new record high of 2648 in $2016 .{ }^{3}$ However, a high mobility of minors within the football industry at the same time raises questions about their welfare and rights. ${ }^{4}$ In particular, the exposure of young players to emotional and physical harm, financial exploitation, and human trafficking through engaging with football has been documented. ${ }^{5}$ With a view to protecting

Serhat Yilmaz

s.yilmaz3@lboro.ac.uk

1 Lecturer in Sports Law, School of Sports, Exercise and Health Sciences, Loughborough University, Loughborough LE11 3TU, UK minors from the detrimental impacts of such practices, FIFA has developed a regulatory framework composed of a set of provisions within its Regulations on the Status and Transfer of Players (RSTP) that governs the international transfer of minors. Originally adopted and introduced in the RSTP in 2001, this framework went through modifications in 2005, 2009, and 2015 to expand its scope to improve the protection given to young players. ${ }^{6}$ The Court of Arbitration for Sport (CAS) has been an integral part of this regulatory regime for not only being a supreme arbitral

\footnotetext{
${ }^{1}$ For the purposes of the paper, the definition of 'minor' is adopted from the FIFA Regulations on the Status and Transfer of Players (RSTP) (2018) as 'a player who has not yet reached to the age of 18'.

2 Rowe (2016), pp. 33-39.

${ }^{3}$ FIFA Transfer Matching System, Global Transfer Market Report 2017, https://www.fifatms.com/data-reports/reports/ (Accessed 10th Dec 2017).

${ }^{4}$ For details see Donnelly and Petherick (2004), Brackenridge et al. (2006), and Darby et al. (2007).

5 For details see Esson (2015a, 2015b), Stafford et al. (2015), and Eliasson (2017).

${ }^{6}$ For a detailed historical overview of the system until 2011, see Lembo (2011).
} 
authority resolving disputes related to the violations of the framework by football stakeholders but, more importantly, for also clarifying its practical operation through its jurisprudence by examining and interpreting its specific provisions. The Acuña case, ${ }^{7}$ the $F C$ Midtjylland case, ${ }^{8}$ the Elmir Muhic case, ${ }^{9}$ and the Vada I and Vada II cases $^{10}$ are amongst some of the important CAS decisions that have shaped the evolution of the regulatory framework for minors within football. ${ }^{11}$

Building on the existing, but rather a limited literature, on the analysis of the CAS jurisprudence on minors in football, ${ }^{12}$ this paper examines the recent CAS cases that involved two giants of Spanish football, Fútbol Club Barcelona $^{13}$ (hereafter referred as 'Barcelona') and Real Madrid Club de Fútbol ${ }^{14}$ (hereafter referred as 'Real Madrid), and the Spanish national association, the Real Federació Española de Fútbol ${ }^{15}$ (hereafter referred as 'RFEF'). In doing so, this paper aims to synthesise legal reasoning put forward by the CAS panels in the Barcelona and the RFEF cases and the Sole Arbitrator of the Real Madrid case with a view to drawing some conclusions about the practical operation of the regulatory framework for the protection of minors under the RSTP. These cases represent the first time that the CAS has considered the liability of a national association (in this case the RFEF) in relation with the protection of minors, and they provide a valuable insight into the operation of the FIFA framework at a national level. The cases are also the first opportunity

\footnotetext{
${ }^{7}$ CAS 2005/A/955, Cadiz C.F., SAD v. FIFA and Asociación Paraguaya de Fútbol, award of 30th December 2005 and CAS 2005/A/956, Carlos Javier Acuña Caballero v. FIFA and Asociación Paraguaya de Fútbol, award of 30th December 2005.

${ }^{8}$ CAS 2008/A/1485, FC Midtjylland A.S v. Fédération Internationale de Football Association.

${ }^{9}$ CAS 2011/A/2354, E. v. Fédération Internationale de Football Association (FIFA), award of 24th August 2011.

10 CAS 2011/A/2494, FC Grondins de Bordeaux v. FIFA, award of 17 May 2011 (in French), CAS 2012/A/2682, FC Grondins de Bordeaux v. Fédération Internationale de Football Association (FIFA), award of 11th January 2013 (in French).

${ }^{11}$ For extensive analysis of some of these cases see Lembo (2011), Derung (2015), and an excellent a three-part blog of Mekenkamp Kester on Asser International Sports Law Blog, FIFA's Provisions on the Protection of Minors, 12th December 2016, http://www.asser.nl/ SportsLaw/Blog/post/fifa-s-provision-on-the-protection-of-minorsand-eu-law-part-1-the-early-years-by-kester-mekenkamp (Accessed 5 th Nov 2017).

12 See supra note 11.

13 CAS 2014/A/3793, Fútbol Club Barcelona v. Fédération Internationale de Football Association (FIFA), award of 24th April 2015 (operative part 30th December 2014).

14 CAS 2016/A/4785, Real Madrid Club de Fútbol v. FIFA, award of 3rd May 2017 (operative part notified on 20 December 2016).

15 CAS 2014/A/3813, Real Federación Española de Fútbol (RFEF) v. Fédération Internationale de Football Association (FIFA), award of 27th November 2015.
}

for CAS to rule on the application of the RSTP beyond Art. 19 and to consider specific procedural requirements in relation with minors, such as the requirement in Art. 5 for players to be registered and the necessity for an international transfer certificate (ITC). The cases involved numerous young players and multiple regulatory infringements, and highlight the complex relationship and interaction between different regulatory obligations under the RSTP. They are important for appreciating overall the regulatory framework that governs the international transfer of minors.

This paper proceeds in three steps. First, it presents an overview of the regulatory framework for the protection of minors under the RSTP with its specific provisions. The overview provides a holistic view of the framework incorporating not only Art. 19 but also other specific provisions of the RSTP that are also applicable to minors. This initial analysis of the paper is formulated from the examination of the CAS awards in three Spanish cases, yet presented first with an intention to provide the legal context of the analysis within the paper's following sections. Then, the paper moves on to synthesise legal reasoning of the CAS panels and the Sole Arbitrator in all three cases to underline some key legal principles that emerge in relation with the operation of the regulatory framework in practice. Finally, the paper highlights the key features of the regulatory framework that football stakeholders, in particular national associations and clubs, should observe when dealing with minors.

\section{An overview of the regulatory framework for the protection of minors in the FIFA RSTP $^{16}$}

Academic works that study the regulatory framework for minors have generally focused on Art. 19 of the RSTP. ${ }^{17}$ This approach is rightly so as Art. 19 is the central provision of the RSTP that sets out fundamental principles of the regulatory regime established by FIFA. Nonetheless, as the analysis of this paper illustrates in the following sections, in practice, Art. 19 does not operate in a vacuum. It intertwines with other provisions of the RSTP which are in essence administrative requirements related to the transfer of players in general, hence applicable to minors too. It is, therefore, essential to delineate a comprehensive picture of

\footnotetext{
${ }^{16}$ Unless stated otherwise, from now on, the specific provisions are referenced according to the latest version of the regulations, the FIFA RSTP 2018, which came into force on 1st January 2018, http:// resources.fifa.com/image/upload/regulations-on-the-status-and-trans fer-of-players-2018.pdf?cloudid=dpeoteqewj8f5doahly7 (Accessed 25th Mar 2018).

17 Supra note 11.
} 
the framework under the RSTP, which this part of this paper aims to do, to better capture its operation in practice. Moreover, each provision of the framework that is elaborated below serves different purposes in accomplishing its overall objective, i.e. protecting minors. Substantive provisions set out key principles of the framework, whereas others are procedural that establish the administrative requirements of the framework to allow the football governing bodies to monitor the compliance with the substantive requirements. This distinction is especially important in assessing the seriousness of regulatory violations committed by any party in dealing with young players and in establishing the level and proportionality of sanctions. Against this background, this section now moves on to outline specific provisions of the framework in line with their distinctive natures.

\subsection{Substantive provisions}

\subsubsection{Art. 19.1 of the RSTP: the prohibition on the international transfer of minors}

Art. 19.1 of the RSTP is the primary substantive provision of the framework that establishes a general rule by strictly prohibiting the international transfer of minors. The ban on the international movement of young players intends to guarantee their welfare and to curb potential detrimental practices such as their exploitation and trafficking. ${ }^{18}$ FIFA aims to ensure a strict implementation of the rule and only allows transfers involving minors in exceptional circumstances that are set out under Art. 19.2 of the Regulations.

\subsubsection{Art. 19.2 of the RSTP: the statutory exceptions to the prohibition}

There are three statutory exceptions to the prohibition; the parents rule, the EU-EEA rule, and the $50+50$ rule. One of these exceptions must be met in order for an international transfer of a minor to take place. The parents rule permits the international transfer of minors if their family moves to the country of the new club for a reason that is not linked to football. ${ }^{19}$ The EU-EEA rule enables minors aged between 16 and 18 to be transferred within the European Union (EU) and the European Economic Area (EEA) provided that their new clubs guarantee their sporting training in line with the highest national standards, their academic/educational training to allow the players to

\footnotetext{
18 These specific objectives were outline by FIFA in its Circular that introduced the provisions in the RSTP 2001. See FIFA, Circular No. 769, 24th August 2001, https://resources.fifa.com/mm/document/ affederation/administration/ps_769_en_68.pdf (Accessed 19th Aug 2017).

${ }^{19}$ FIFA, RSTP 2018, Article 19.2(a).
}

pursue an alternative career if they cease playing football, and arrangements to ensure their welfare in the best possible way. ${ }^{20}$ The $50+50$ rule takes into account the situation of young players living within the vicinity of borders and enables those who live no further than $50 \mathrm{~km}$ of a national border to register with a club in a neighbouring association which is also located within $50 \mathrm{~km}$ of the national border. ${ }^{21}$ The rule takes an effect only if there is a maximum distance of $100 \mathrm{~km}$ between the player's domicile and the club's headquarters and the minor must continue to live at home.

\subsubsection{Art. 19.3 of the RSTP: the first registration of minors}

The prohibition on the international transfer of minors also extends to first registrations of non-national minors. To explain, if a minor has never previously been registered with a club and is not a national of the country in which he wishes to be registered with a club for the first time, then that first registration is also prohibited unless one of the exceptions under Art. 19.2 is fulfilled. Because not every young player is registered with a club at an early age, the main objective of Art. 19.3 is to extend the protection given to minors also in the case of their first registration with a club in another country. This provision at the same time underscores an important distinction between an international transfer, that is the registration of a minor who has been already registered with a club in one country and moves to another country to affect that registration with another club, and a first registration, that is the registration of a minor who has never been registered before.

What is worth noting is that a new exception applicable to the first registration of minors, in addition to the three exceptions under Art. 19.2, has been recently introduced into the framework. ${ }^{22}$ The 5-year rule, which came into effect on 1st June 2016, allows the first registration of a minor with a club in a country that the player is not a national but has continuously lived for at least 5 years immediately prior to the intended first registration. ${ }^{23}$

Beyond the three exceptions under Art. 19.2 and the 5 -year rule under 19.3 of the RSTP, there are also two more exceptions to the prohibition of the international transfer of minors established through the jurisprudence of the FIFA

\footnotetext{
${ }^{20}$ FIFA, RSTP 2018, Article 19.2(b).

21 FIFA, RSTP 2018, Article 19.2(c).

${ }^{22}$ FIFA, Circular No.1542, 1st June 2016, http://resources.fifa.com/ $\mathrm{mm} /$ document/affederation/administration/02/79/97/47/circularno. 1542-amendmentstotheregulationsonthestatutsandtransferofplayers_ neutral.pdf (Accessed 24 Sept 2017).

${ }^{23}$ FIFA, RSTP 2018, Article 19.3 and 19.4.
} 
Sub-Committee ${ }^{24}$ and the CAS. ${ }^{25}$ In particular, the SubCommittee exceptionally accepts applications regarding to unaccompanied refugee players and exchange student players. The unaccompanied refugee players are those who move to another country without their parents due to humanitarian reasons and could not be expected to return to their country of origin because of a danger to their life or freedom. The exchange student players on the other hand are those whose movements to another country without his/ her parents are primarily for educational reasons and their maximum registration periods with respective clubs do not exceed a year provided that they return home immediately after the end of their educational programmes or turn 18 before the end of the programmes.

\subsection{Procedural provisions}

\subsubsection{Art. 19.4 RSTP: the rules concerning administrative aspects of the international transfer and the first registration of minors}

Art. 19.4 represents an effort to further strengthen the protection of minors in football and establishes procedural mechanisms of the regulatory framework. ${ }^{26}$ The SubCommittee, which is appointed by the FIFA Players' Status Committee (PSC), is authorised to inspect and approve every international transfer and every first registration of minors in football. National associations are required to submit an application to the Sub-Committee to seek an approval before registering any minor. In addition, the procedural mechanisms also incorporate a mandatory use of FIFA's Transfer Matching System (TMS), the web-based information processing system for

\footnotetext{
${ }^{24}$ In 2009, FIFA established a sub-committee appointed by its Players' Status Committee as a new supervisory body for the international transfer of minors. The Sub-Committee is responsible for the examination of every international transfer and every first registration of minors in football. Procedurally, the approval of the Sub-Committee is required in order for the transfer to take place.

${ }^{25}$ For more details on these two exceptions see FIFA, Minor Player Application Guide, 23rd February 2017,

http://resources.fifa.com/mm/document/affederation/footballgover nance/02/86/35/28/protectionofminors-" minorplayerapplication guide"_neutral.pdf (Accessed 24 Sept 2017).

${ }^{26}$ FIFA, Circular No.1190, 20th May 2009, http://resources.fifa.com/ $\mathrm{mm} /$ document/affederation/administration/01/06/29/81/circularno. 1190-revisedregulationsonthestatusandtransferofplayers-protectionof minors.pdf (Accessed 24th Sept 2017).
}

international transfers ${ }^{27}$ for the international transfer and the first registration of minors. ${ }^{28}$

\subsubsection{Annexe 2 RSTP: procedure governing applications for first registration and international transfer of minors}

Annexe 2 of the RSTP elaborates on the procedural mechanisms established under Art. 19.4. The approval applications to the Sub-Committee for the international transfer of a minor satisfying the exceptions of Art. 19.2 or the first registration of a minor pertaining to Art. 19.3 must be lodged and managed through the TMS. ${ }^{29}$ The responsibility to enter these applications into the TMS is with national associations rather than clubs. There are also specified mandatory documents that must be submitted to support the applications. ${ }^{30}$ These documents must prove that the international transfer or the first registration of the minor in question fits into the one of the exceptions and are examined by the Sub-Committee for the purposes of verification.

\subsubsection{Annexe 3 RSTP: the use of the transfer matching system (TMS) for the purposes of the protection of minors}

Annexe 3 provides the legal basis for the TMS and highlights a further commitment to use the system for the protection of minors. Annexe 3 requires a national association that wishes to register minors relying on an exception outlined in Arts 19.2 and 19.3 to seek the approval of the Sub-Committee and to use TMS. ${ }^{31}$

\subsubsection{Art.19bis RSTP: registration and reporting of minors at academies}

Clubs that operate academies with either legal, financial or de facto links are required to report all minors attending their academies to associations upon whose territory the academy in question operates. ${ }^{32}$ Associations, on the other hand, are obliged to ensure that all academies within their territories without legal, financial or de facto links to a club

\footnotetext{
${ }^{27}$ For further details on the TMS see the details published by FIFA, 30th September 2010, http://www.fifa.com/governance/news/y=2010/ $\mathrm{m}=9 /$ news $=$ the-tms-explained-1310345.html (Accessed 28th September 2017).

${ }^{28}$ FIFA, Circular No. 1205, 23rd September 2009, http://resources. fifa.com/mm/document/affederation/administration/01/10/77/60/circu larno.1205-fifatmstransitionphase.pdf (Accessed 24 Sept 2017).

${ }^{29}$ FIFA, RSTP 2018, Annexe 2, Para. 1.1.

${ }^{30}$ FIFA, RSTP 2018, Annexe 2, Paras. 5.2-5.3.

31 FIFA, RSTP 2018, Annexe 3, para 1.3; and Arts 19.2-19.4.

${ }^{32}$ FIFA, RSTP 2018, Art. 19bis.1.
} 
report all their players to the association and also all minors attending the academy for the purposes of training. ${ }^{33}$ In addition, associations are also required to keep a register of minors comprising names and the dates of birth of the reported minors by clubs and academies within their territories. ${ }^{34}$

\subsection{Other procedural provisions of the RSTP applicable to the transfer of minors}

Beyond the procedural requirements under Art. 19, in particular Art. 19.4 read in conjunction with Annexes 2 and 3, and Art. 19bis of the RSTP, there are some further procedural rules set out in the RSTP applicable to all international transfers in football including the international transfers or first registrations of minors.

\subsubsection{Art. 9 RSTP: international transfer certificate (ITC)}

A key procedural requirement for any international transfer is the issuance of the ITC by the player's former association to the new association within whose territory his/her new club is based. Unless the ITC is received, the new association may not register the player. ${ }^{35}$ The ITC is also required for an international transfer of a minor. One of the important functions of the ITC is to assist the calculation and arrangement of training compensation which is payable for players between the ages of 12 and 23 when they sign their first professional contract and thereon each time they are professionally transferred until the end of the season of their 23rd birthday. ${ }^{36}$ Historically, because of the minimum age limit for the liability of the training compensation, the ITC was not required for transfers involving players under the age of 12. Nevertheless, due to an increased number of international transfers of players younger than 12 years, FIFA has reduced the age limit for the requirement of the ITC to 10 years with an effect from 1st March $2015 .{ }^{37}$ The change was reflected in the wording of Art. 9.4 of the RSTP. As a result, from the date that the new age limit of the ITC came into force, national associations are obliged to seek the approval of the SubCommittee for the international transfers or first registrations of any players of the age of 10 and above. In addition, in the communication outlining the rule change, FIFA also re-emphasised the duty of national associations to verify

\footnotetext{
${ }^{33}$ FIFA, RSTP 2018, Art. 19bis.2(b).

${ }^{34}$ FIFA, RSTP 2018, Art. 19bis.3.

35 FIFA, RSTP 2018, Art. 9.1.

36 FIFA, RSTP 2018, Art. 20.

37 FIFA, Circular No. 1468, 23rd January 2015, http://resources.fifa. $\mathrm{com} / \mathrm{mm} /$ document/affederation/administration/02/51/06/50/circu larno.1468_e_neutral.pdf (Accessed 18 Oct 2017).
}

and ensure the regulatory framework for the protection of minors is fully respected at the national level. It especially clarified that the exceptions of Art. 19.2 of the RSTP should be fulfilled in the case of the international transfer or first registration of any minor under the age of 10 despite the ITC or the approval of the Sub-Committee are not required. ${ }^{38}$

\subsubsection{Art. 5 RSTP: registration of players}

The final procedural requirement that applies to minors is the registration requirement to play for a club either as a professional or an amateur. ${ }^{39}$ The registration is a prerequisite for any player to be eligible to participate in organised football that is defined as association football organised under the auspices of FIFA, the confederations, the associations, or authorised by them. ${ }^{40}$ Minors, therefore, also need to be registered with an association within whose territory their clubs or academies are located to be able to take part in organised football.

\subsection{Governance and operational aspects of the framework}

The regulatory regime for the protection of minors is administered and operated by FIFA at the international level who exercises its executive powers to set out and amend the rules. FIFA also enjoys a supervisory authority to ensure an appropriate implementation of the framework by its member associations. With the introduction of the TMS, FIFA Transfer Matching System GmbH, known as 'FIFA TMS', ${ }^{41}$ the subsidiary of FIFA that manages the TMS, is now delegated with a monitoring responsibility for the applications submitted by associations to the approval of the Sub-Committee for the transfer or the first registration of minors and the relevant ITC requests made through the system. The FIFA TMS is also given investigative powers concerning the compliance of associations and clubs with the procedural requirements of the regulatory framework. $^{42}$ The FIFA Disciplinary Committee is empowered with a judiciary authority combined with sanctioning powers against any regulatory breached committed either by associations and clubs. ${ }^{43}$ At the national

\footnotetext{
38 Ibid.

39 FIFA, RSTP 2018, Art. 5.1.

${ }^{40}$ FIFA, RSTP 2018, Definitions.

${ }^{41}$ For further details on FIFA TMS, see Thatcher Adam, Your Guide to FIFA's Transfer Matching System, 22nd May 2014, https://www. lawinsport.com/topics/articles/regulation-a-governance/item/yourguide-to-fifa-s-transfer-matching-system (Accessed 10 Nov 2017).

42 FIFA, RSTP 2018, Annexe 2, Para. 4.3.

${ }^{43}$ FIFA, RSTP 2018, Art. 19.4.
} 
level, the onus of the framework is on national associations. They enjoy a supervisory authority within their respective territories to ensure that their affiliated members, i.e. regional associations and clubs, adhere to the framework and comply with its requirements. National associations are also required to transpose the specific provision of the framework, namely Art. 19, Art. 19bis, and Art. 5 of the RSTP, into their domestic regulations without any modification. ${ }^{44}$ This implementation measure aims to ensure a level of coherency and consistency in the operation of the framework at both the national and international levels without any form of derogation from substantive and procedural requirements.

\section{Analysis of the Spanish cases at the CAS}

\subsection{The background of the cases}

Before engaging in the analysis of the Spanish cases by the CAS, it is important to note two principal contributory factors that led to the violations of the framework in Spain by the RFEF, Barcelona and Real Madrid in their dealings with minors. These factors came to light during the proceedings before the CAS and were also utilised to form the basis of legal arguments put forward by the Spanish parties against the decisions of FIFA's adjudicatory bodies.

\subsubsection{Spanish sports governance system}

Established under the Spanish Law, in particular under Art. 148 of the Constitution and the Law on Sport (Ley 10/1990), the Spanish sports governance system operates through 17 autonomous regions, Comunidades Autónomas, who enjoy territorial competency in the field of sport. Each region has its own sports associations governing their respective sports in coordination with national associations. In terms of football, as a result, the regional associations, such as the Federación Catalan de Futbol (hereafter referred as 'FCF') in Catalonia and the Federación Futbol de Madrid (hereafter referred as 'FFM') in Madrid, are responsible for regulating and administering football in their respective territories. These regional associations also handle the licensing and registration of players to participate in their regional competitions. The registration of players with the RFEF, as the national association in Spain, is only required if players are to participate in national competitions. Clubs are also mandatorily affiliated with the regional associations within whose territory they are based and must

$\overline{44}$ FIFA, RSTP 2018, Art. 1.3. adhere to their rules and regulations. ${ }^{45}$ Consequently, the ramification of the national governance system for the international transfer of minors or first registration of minors is the operation of a three-stage system under which clubs initiate the transfer or the first registration process firstly with the regional associations who correspond with the RFEF who then undertakes procedural steps in accordance with the RSTP. ${ }^{46}$ In practice, therefore, both Barcelona and Real Madrid had historically been licensing and registering their minors directly with the FCF and the FFM rather than with the RFEF and not always following the right procedural mechanisms for their transfers or first registrations, i.e. registering minors without either satisfying the exception of Art. 19.2 of the RSTP or seeking the approval of the Sub-Committee in line with Art. 19.4 with Annexes 2 and 3 .

\subsubsection{Interpretation of the applicability of Art. 19 of the RSTP to the players under the age of 12}

There was a confusion about the implications of Art. 9.4 of the RSTP, the provision that sets the age limit for the ITC requirement, for the transfer of players under the age of 12 , in particular the applicability of the regulatory framework to minors of that age category or below. The RFEF had misinterpreted the non-existence of the ITC requirement for the players under the age of 12, as per Art. 9.4, and assumed that clubs were not required to fulfil one of the exceptions of Art. 19.2 or to have the authorisation neither from the RFEF or the Sub-Committee for the international transfer or first registration of minors at the age of 12 or below. ${ }^{47}$ In other words, the RFEF interpreted the nonrequirement of the ITC for the U-12 players as an exemption from the application of the regulatory regime. The RFEF's understanding was discernible in the response sent to Real Madrid on 10th March 2014 following the Club's inquiry to seek clarity with regard to the correct procedure for players under the age of 12 . The RFEF confirmed that neither its approval nor the approval by the Sub-Committee was required for the transfer or the first

\footnotetext{
$\overline{45}$ For details of the national governance system in Spain, see CAS 2014/A/3793, Fútbol Club Barcelona v. Fédération Internationale de Football Association (FIFA), award of 24th April 2015 (operative part 30th December 2014), para. 4.1.2.a, CAS 2014/A/3813, Real Federación Española de Fútbol (RFEF) v. Fédération Internationale de Football Association (FIFA), award of 27th November 2015, paras. 64-68, CAS 2016/A/4785, Real Madrid Club de Fútbol v. FIFA, award of 3rd May 2017 (operative part notified on 20 December 2016), para. 36.d.

46 CAS 2014/A/3813, para. 69.

47 CAS 2014/A/3793, para. 4.1.2.f, CAS 2014/A/3813, para. 31, CAS 2016/A/4785, para. 55 .
} 
registration of the players of that age category and regional associations were supposed to register them 'without further action' ${ }^{48}$ Following Real Madrid's inquiry, the RFEF wrote to FIFA on 10th April 2014 asking for the clarification of the situation. ${ }^{49}$ In its response on 17th April 2014, FIFA confirmed that

'...there was no need to seek approval under Art.19.4 of the RSTP before requesting an ITC and/or affecting a first registration of a player aged below 12 years... However, any association intending to register minors aged below 12 years for one of its affiliate clubs carries a greater responsibility of ensuring that the well-being in question is not under threat and that they are treated in line with the spirit and principles of relevant regulations on the protection of minors'. 50

However, the response by FIFA did not rectify the misunderstanding of the rule by the RFEF; instead it was actually the FIFA Circular no.1468 of 23rd January 2015 brought a much-needed clarity. The Circular not only introduced the age limit of 10 for the ITC but also cleared up the procedure concerning the U-10 players by underlining that

'despite the fact that no ITC and no application to the sub-committee appointed by the Players' Status Committee will be required, it is all the more responsibility of this association to verify and ensure that the requirements for the protection of minors established under art 19 par 2. are met'. ${ }^{51}$

Subsequently, the RFEF issued two circular letters, the Circular no. 33 of 26th January 2015, and the Circular no. 37 of 3rd February 2015, to explain the amendments of the RSTP and especially underscored that '...in no case will a foreign or non-national player under 10 years of age be registered without the prior authorization of the RFEF, ${ }^{52}$ Nonetheless, during the period prior to the FIFA Circular in 2015, both Barcelona and Real Madrid had registered players under the age of 12 with their respective regional associations without any verification concerning the fulfilment of any of the exceptions or without any approval from the RFEF or the Sub-Committee.

\footnotetext{
48 CAS 2016/A/4785, para. 55.

49 CAS 2014/A/3813, para. 27.

50 CAS 2014/A/3813, para. 29, CAS 2016/A/4785, para. 8.

51 CAS 2014/A/3813, para. 29, CAS 2016/A/4785, para. 55.

${ }^{52}$ CAS 2016/A/4785, para. 11.
}

\subsubsection{The proceedings before the judicial bodies of FIFA}

The peculiarities of the Spanish football system outlined above eventually came to light following a monitoring exercise by the FIFA TMS in January 2013 which highlighted a potential breach of the RSTP by Barcelona in relation with a transfer of a minor that was registered with the Club. The FIFA TMS sought further information from both the Club and the RFEF to ascertain the regulatory breach. In the course of the information exchange in February 2013, the RFEF disclosed that another minor player was registered with the Club which subsequently led to a further investigation into the registration of 31 minors with the regional association, the FCF, as the players of Barcelona for the period from 2005 until 2012. Amongst them, 9 minors had been previously registered with overseas clubs, 5 minors had never been previously registered with a club, 21 minors were under the age of 12 at the time of their registration with the FCF, and none of the minors had been directly registered with the RFEF. In addition, it also came to light that the RFEF had never received the ITC for 6 of 9 minors that were previously registered with another clubs and never filed any application with the SubCommittee to seek the approval for the international transfer or the first registration of 7 of 31 minors.

As a result of the FIFA TMS investigation, the FIFA Disciplinary Committee initiated disciplinary proceedings against both the RFEF and Barcelona on 25th September 2013 and sanctioned them on 28th November 2013 for various violations of the regulatory regime for the protection of minors in the RSTP. With regard to Barcelona, the Committee concluded that the Club breached the prohibition under Art. 19.1 in the international transfers of 9 minors and Art. 19.3 in the first registration of a non-national minor by failing to meet any exceptions of Art. 19.2. The Club also violated Art. 19.4 in conjunction with Annexes 2 and 3 because of its failure to seek the approval of the Sub-Committee in relation with the international transfers of 6 minors and to utilise the TMS in 5 of those transfers since the introduction of the mandatory use of the system in 2010. Furthermore, Art. 9.1 was breached in the international transfers of 6 minors as the Club registered them without the receipt of the ITC from relevant former associations and Art. 5.1 was violated in all 31 cases due to the failure of the Club to register them with the RFEF rather than the FCF who is not recognised as a competent association by FIFA for the purposes of the RSTP. Finally, Barcelona also breached Art. 19bis in all 31 cases as none of the minors were reported or registered with the RFEF despite attending the Club's academy. ${ }^{53}$ As a consequent, the Club was banned from signing players at the national

\footnotetext{
${ }^{53}$ CAS 2014/A/3793, para. 2.15.
} 
and international levels for a period of two consecutive transfer windows following the notification of the decision by the FIFA Disciplinary Committee, sanctioned with a payment of a fine in the amount of CHF 450,000, issued with a reprimand, and given 90 days to review the situation of the minors at the Club. ${ }^{54}$

With regard to the RFEF, the FIFA Disciplinary Committee also concluded that the body committed breaches in relation with: Art 19.1 of the RSTP in the international transfer of 9 minors and Art. 19.3 in the first registration of 5 minors due to failing its duty to ensure the compliance of its football stakeholders, i.e. clubs, with the regulatory framework for the protection of minors; Art. 19.4 in conjunction with Annexe 2 in the international transfers or the first registration of 7 minors and Art. 19.4 in conjunction with Annexe 3 in the international transfer or the first registration of 6 minors because of its failure to seek the approval of the Sub-Committee and to follow right procedural steps; Art. 9.1 in the international transfer of 6 minors due to its failure to request the ITC from the former associations; and Art. 5.1 in all 31 minors because of failing to ensure the registration of the players with itself rather than with the FCF whilst allowing them to participate in organised football. ${ }^{55}$ The RFEF was fined CHF 500,000, issued with a reprimand, and granted a 1-year period to rectify the problem with the application of the regulatory framework at the national level. ${ }^{56}$ The RFEF and Barcelona appealed before the FIFA Appeals Committee and both decisions were upheld on 14th August 2014. ${ }^{57}$ Both parties subsequently brought proceedings before the CAS against FIFA.

Coinciding with FIFA's disciplinary proceedings against the RFEF and Barcelona, the FIFA TMS also noticed a potential breach of the framework by Real Madrid in relation to 3 minors in October 2013. Following a request for further information, Real Madrid submitted the details of several other minors who were registered with the Club by the FFM. As a result, the FIFA Disciplinary Committee commenced a preliminary investigation on 11th November 2014 with a view to assessing whether Real Madrid had committed any violation of the RSTP and subsequently launched disciplinary proceedings on 27th March 2015. Investigating registrations of 70 minors, the Committee concluded that the Club also violated various provisions of the RSTP in the same way as Barcelona. Art. 19.1 was breached in the international transfers of 4 minors and Art. 19.3 in the first registrations of 4 non-national minors as the Club failed to invoke any exceptions of Art. 19.2 of the RSTP. Real Madrid also violated Art. 19.4 in conjunction

\footnotetext{
${ }^{54}$ CAS 2014/A/3793, para. 2.14, CAS 2014/A/3813, para.26.

55 CAS 2014/A/3813, para. 25.

56 Ibid.

57 Ibid., para. 32 and para. 34.
}

with Annexes 2 and 3 in relation with the international transfers or first registrations of 4 minors due to its failure to seek the approval of the Sub-Committee and to use the TMS. Furthermore, in the international transfer of one minor, the registration took place without the receipt of the ITC from the player's former association, hence the Club breached Art. 9.1 of the RSTP. Real Madrid also violated Art. 5.1 in the transfer of 33 minors because it registered them with the FFM rather than directly with the RFEF and Art. 19bis in relation with 38 minors due to failing to report or register them directly with the RFEF. ${ }^{58}$ As a result, Real Madrid was also banned from registering any players, either nationally or internationally, for two entire and consecutive registration periods, fined CHF 360,000, issued with a reprimand, and given 60 days to rectify the situation of minors at the Club. ${ }^{59}$ Real Madrid's appeal to the FIFA Appeals Committee was rejected on 8th April 2015 and the Club initiated proceedings before the CAS on 27th September 2015. ${ }^{60}$

\subsection{Key findings of the CAS panels in the Barcelona and the RFEF cases and the sole arbitrator in the Real Madrid case}

\subsubsection{The responsibility and the liability of national associations in relation with the operation of the regulatory system of the FIFA RSTP}

The first important legal issue considered was the responsibility and the liability of national associations in relation with the regulatory regime of the protection of minors under the RSTP. This was the first time that a national association had been sanctioned in connection with the protection of minors. ${ }^{61}$ All three appellants, the RFEF, Barcelona, and Real Madrid, attempted to absolve themselves from any liability and responsibility by blaming the fragmented national governance structure that is established by the Spanish law and operating in Spain. The RFEF contested its liability for the breaches of the RSTP and attempted to impute responsibility on the FCF and Barcelona. The national governing body relied upon exclusive powers given to the FCF under the laws of Catalonia to license players to participate in regional competitions and argued that interfering with the licensing system at the regional level would amount to the excess of its powers under the Spanish law. ${ }^{62}$ Moreover, the RFEF

\footnotetext{
58 CAS 2016/A/4785, para. 12.

59 Ibid., para. 14.

60 Ibid. para. 16.

${ }^{61}$ CAS 2014/A/3813, para. 290.

${ }^{62}$ Ibid., para. 84.
} 
also claimed that it cannot be held liable for the acts or omissions committed by the FCF and Barcelona who failed to comply with the requirements of the system under the RSTP. ${ }^{63}$ The compliance of the RFEF with the framework cannot be expected due to its lack of knowledge about minors in regional competitions unless players were brought to its attention via petitions received from Barcelona or the request made by the FCF. ${ }^{64}$ Barcelona and Real Madrid argued that they are by law mandatorily affiliated to their respective regional associations, the FCF and the FFM, and obliged to comply with their regulations concerning the licensing and the registration of players. Barcelona argued that when dealing with minors, it fully complied with the procedures put in place by the FCF, while Real Madrid claimed that it had to register the minors in question with the FFM rather than directly registering with the RFEF because the players only participated in the regional competitions. ${ }^{65}$

3.2.1.1 The RFEF case The Panel of the RFEF case dealt with the responsibility and liability of the RFEF in greater detail than the Panel of the Barcelona case and the Sole Arbitrator of the Real Madrid case. In its view national associations 'are the primary guardians of FIFA's regulations on the protection of minors ${ }^{\prime 66}$ and have an oversight responsibility to ensure the protection of minors by making sure that their members, i.e. clubs, fully comply with the regime under the RSTP. ${ }^{67}$ This supervisory responsibility derives from the status of national associations in charge of running the football at the national level and by the virtue of their position as FIFA's members. They are obliged by Art. 13.1.(d) of the FIFA Statutes 'to ensure that their own members comply with the Statutes, regulations, directive, and decisions of FIFA bodies'. ${ }^{68}$ The Panel added that this responsibility comes with a duty of care that all national football associations are entrusted by FIFA to ensure their clubs comply with the provision of the RSTP. ${ }^{69}$ The breach of that duty eventually renders national associations, in casu the RFEF, liable for the violations of the RSTP even though the breaches are committed by their members. Therefore, the Panel rejected the RFEF's arguments and asserted that the RFEF failed to perform its oversight role or fulfil its duty of care by ensuring the compliance of its members with the RSTP. ${ }^{70}$ According to the Panel, the

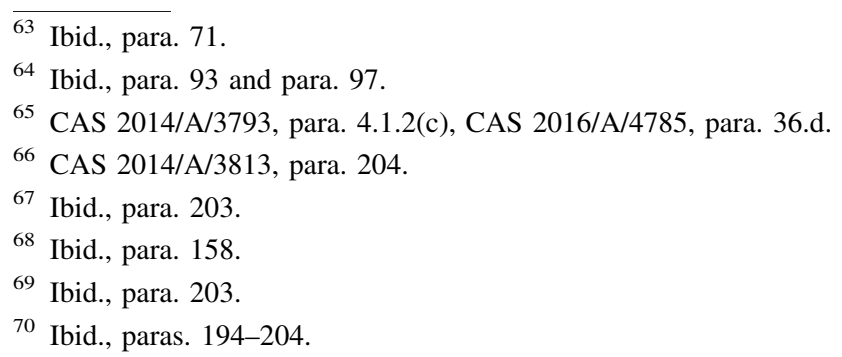

failure was the result of the RFEF's inaction in undertaking neither preventive nor curative measures, especially in monitoring its members' compliance with the regime, while passively allowing the prolonged regulatory breaches by the FCF and Barcelona. ${ }^{71}$ To that effect, the Panel concluded that the RFEF by default or omission breached the specific provisions of the RSTP in question and was liable for the consequences. ${ }^{72}$ With regard to the conflict between the Spanish law and the RSTP, the Panel was not satisfied that the RFEF had clearly established the existence of a conflict or the effect of such conflict in preventing the appellant from complying its role and the duty as a FIFA member. ${ }^{73}$

3.2.1.2 The Barcelona and Real Madrid cases The oversight responsibility of national associations to ensure the compliance with the regulatory regime of the protection of minors in the RSTP at the national level is also underlined in both the Barcelona and the Real Madrid cases. In establishing the responsibility, however, the Panel of the Barcelona case considered the basis and the main rationale of the RSTP. The Panel noted that the RSTP inter alia aims to govern the international transfer of players between national associations which in turn implies that activities related to the transfers and first registrations of minors should remain in the hands of national associations. The national governing bodies should not confer this duty to regional associations. ${ }^{74}$ In elaborating on its legal reasoning, in addition, the Panel followed a strict interpretation of rules and regulations of FIFA and the meaning of terms therein. The definition of 'association' in the FIFA Statutes, that is 'a football association recognised by FIFA. It is a member of FIFA, unless a different meaning is evident from the context' was taken into account. ${ }^{75}$ In this respect, it was clear to the Panel that the FCF is a separate entity established and operated under the Spanish sports governance system and not a FIFA member or an association for the purposes of the RSTP. In contrast, the Panel of the case completely disregarded the Spanish law, and the peculiarities of the Spanish football governance system, despite acknowledging the applicability of domestic law in the case. ${ }^{76}$ As a result, it was ruled that 'association' that is responsible to maintain the regulatory regime and conduct

\footnotetext{
$\overline{71}$ Ibid., para. 241 and para. 278.

72 Ibid., para. 235 in relation to the breach of Art. 19.1, para. 243 in relation to the breach of Art. 19.3, para. 252 in relation to the breach of Art. 19.4 with Annexes 2 and 3, para. 271 in relation to the breach of Art. 5.1, para. 279 in relation to the breach of Art. 9.1.

73 Ibid., para. 193.

${ }^{74}$ CAS 2014/A/3793, para. 9.2.

75 Ibid.

76 Ibid., para. 8.1 and para. 8.3.
} 
an actual control and registration of minors in Spain is the RFEF, not the regional association, i.e. the FCF. ${ }^{77}$ The similar reasoning concerning the role and duty of national association with regard to the framework for the protection of minors was also followed by the Sole Arbitrator of the Real Madrid case. ${ }^{78}$

\subsubsection{The applicability of Art. 19 of the RSTP to minors under the age of 12}

The second issue examined in all cases was the correct procedure for the international transfer of minors and the first registration of non-national minors under the age of 12 , the minimum age limit applicable at the time violations for the purposes of the ITC requirement before the decision of FIFA in 2015 reducing the age limit to 10 years. This was due to the existence of confusion at the national level because of a misinterpretation of the rule under Art. 9.4, a point explained in the Sect. 3.1.2 above. In this respect, all three appellants argued the inapplicability of Art. 19 of the RSTP to the players under the age of 12 as they believed such minors were not subject to the ITC requirement, with the effect that there had been no violations in relation with 21 minors in the RFEF case, 3 minors in the Barcelona case and 4 minors in the Real Madrid case. ${ }^{79}$ To support the validity of their arguments, all appellants relied upon the same evidence; a commentary added to Art. 9 of the RSTP by FIFA in 2006. The commentary stated that

'for the player younger than 12, the Regulations do not provide for an obligation to issue an ITC for international transfers. This avoids placing a supplementary burden on the association. Furthermore, the age of 12 have no effect in relation to the provisions of the regulations, since the training compensation and solidarity mechanism are calculated only as from this age ${ }^{80}$

Furthermore, both Barcelona and Real Madrid went on to claim that the principle of contra proferentem must apply against FIFA. Real Madrid argued that the Club relied upon both the interpretation of the rule by the RFEF in its letter of 10th March 2014 and the FIFA commentary and also stressed that the confusion was the result of an ambiguity within Art. 9.4 and Art. 19 of the RSTP. According to the Club, this ambiguity was rectified by FIFA for the first time in its Circular no. 1468 in 2015

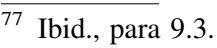

78 See CAS 2016/A/4785, para. 59 and para. 85.

${ }^{79}$ CAS 2014/A/3793, para. 4.1.2(f), CAS 2014/A/3813, para. 88 and 89, CAS 2016/A/4785, para. 36.b.

${ }^{80}$ CAS 2014/A/3793, para. 9.7, CAS 2014/A/3813, para. 90, CAS 2016/A/4785, para. 36.b.
}

under which the responsibility of national associations to actually verify the compliance of all international transfer and the first registration of the players under the age of 10 with the exceptions of Art. 19.2 of the RSTP was clearly underlined. ${ }^{81}$

3.2.2.1 The RFEF and Barcelona cases In addressing the issue, both Panels in the Barcelona and the RFEF cases distinguished between the functionality of Art. 9 and Art. 19 of the RSTP with regard to the overall operation of the regulatory regime for the protection of minors, with a view to bringing a clarity to the confusion that existed prior to the FIFA Circular no. 1468. According to the Panels, it was necessary to interpret the intention of the drafter in relation with these provisions and, in doing so, each provision should be read within the overall context of the RSTP. ${ }^{82}$ Through analysing the text of each provision, both Panels concluded that the scope of Art. 19 differs from that of Art. 9 of the RSTP. Art. 19 imposes a general prohibition on the transfer of all minors under the age of 18 , hence it is a substantive provision of the regime. In contrast, Art. 9, in particular Art. 9.4, is about the absence of an obligation to issue an ITC for players below the age of 12 , thus it is an administrative procedure setting out a procedural vehicle, i.e. ITC, to make transfers happen. ${ }^{83}$ The Panel of the RFEF case further distinguished the purpose of the ITC in relation with international transfers, that is firstly to facilitate the registration of players with their new associations and secondly, in line with the FIFA commentary, to establish a link between the ITC and the concepts of training compensation and solidarity mechanism. ${ }^{84}$ As a result, both Panels ruled that the exclusion of minors under the age of 12 from the ITC requirements does not affect the obligation of the appellants to comply with the substantial provisions under Art. 19 of the RSTP, in particular to fulfil the requirements of Art. 19.2. ${ }^{85}$ The Panel of the Barcelona case underscored the importance of this distinction between Art 9.4 and Art. 19 of the RSTP to bring clarity in practice and also to establish the relationship of the provisions with each other which in effect enables them to coexist rather than one, i.e. Art. 9.4, to be interpreted to eliminate the scope of the other, i.e. Art. $19 .{ }^{86}$ Moreover, both Panels also confirmed that the correct interpretation of the scope of each provision should not have led to the misunderstanding at the national level at first place. ${ }^{87}$

\footnotetext{
${ }^{81}$ CAS 2016/A/4785, para. 36.b.

82 CAS 2014/A/3793, para. 9.8, CAS 2014/A/3813, para. 211.

83 CAS 2014/A/3793, para. 9.8, CAS 2014/A/3813, para. 215.

${ }^{84}$ CAS 2014/A/3813, para. 214.

85 CAS 2014/A/3793, para. 9.8, CAS 2014/A/3813, para. 216.

86 CAS 2014/A/3793, paras. 9.8-9.9, CAS 2014/A/3813, para. 218.

${ }^{87}$ CAS 2014/A/3793, para. 9.9, CAS 2014/A/3813, para. 221.
} 
3.2.2.2 The Real Madrid case By contrast, the Sole Arbitrator in the Real Madrid did not follow the legal reasoning used by the Panels of the previous two cases. The Sole Arbitrator doubted whether the Spanish clubs were actually required to comply with the Art. 19, in particular to fulfil the exceptions of Art. 19.2 of the RSTP, in the transfers or first registrations of the U-12 players. The Sole Arbitrator was rather critical of FIFA because of its failure to clarify the ambiguity about the rules in practice. There was no FIFA rule which clearly stated the applicability of Art. 19 to players under the age of 12 prior to FIFA Circular no. 1468. In addition, for the Sole Arbitrator, the RFEF's confirmation to Real Madrid on 10th March 2014 to register the U-12 players without any further action was an important indicator of the Spanish football stakeholders' understanding of the inapplicability of Art. 19 to the U-12 players. FIFA failed to clarify the situation in its response to the RFEF on 17th April 2014 and its communication followed a vague and more general approached. ${ }^{8}$ Furthermore, FIFA also failed to apply its regulatory regime to the younger brother of Valentin Vada, who was 5 years and registered with the same clubs as his brother who was 15 at the time in the Vada I case. ${ }^{89}$ In the opinion of the Sole Arbitrator, this was FIFA's own admission of the inapplicability of Art. 19.2 to the minors under the age of $12 .{ }^{90}$ In fact, Circular no. 1468 was considered to be the first opportunity taken by FIFA to clearly emphasise the applicability of the regulatory framework to U-10 players (previously U-12s). For these reasons, the Sole Arbitrator viewed that the legal reasoning of the Panel of the Barcelona case could not be followed ad litteram in the case of Real Madrid. ${ }^{91}$ Due to FIFA's failure to prove the applicability of the regime to the players under the age of 12 before March 2015, it was ruled that Real Madrid had not committed any violations of the RSTP in relation with 4 players who were under the age of 12 at the time of their registrations with the Club. ${ }^{92}$

\subsubsection{The liability of clubs and national associations under Art. 5 of the RSTP in relation with the registration of minors}

The next legal issue considered in all three proceedings was the violations of the registration requirement of the players with the national association before they were allowed to participate in organised football. More

\footnotetext{
88 CAS 2016/A/4785, para. 55.

89 CAS 2011/A/2494 FC Grondins de Bordeaux v. FIFA, award of 17th May 2011 (in French).

90 CAS 2016/A/4785, para. 55.

91 CAS 2016/A/4785, para. 59.

92 CAS 2016/A/4785, para. 60.
}

specifically, the main question was whether, for the purposes of the regulatory regime under the RSTP, the registration of minors with the FCF and the FFM rather than the RFEF was actually sufficient to fulfil the requirements of Art. 5.1 of the RSTP? Both Barcelona and Real Madrid argued that the registration of minors with respective regional associations was obligatory because they are the competent authorities for the licensing and registration of players for regional competitions. For this reason, both clubs claimed that the registrations of minors in question were in compliance with Art. 5.1 of the RSTP. ${ }^{93}$ Through the similar line of argument, the RFEF also disputed its liability for the breach of Art. 5.1 by claiming that minors at Barcelona did not take part in any competition organised by the RFEF and the supervision or the issuance of licenses at the regional level were beyond its control. ${ }^{94}$ In addition, the RFEF alleged that the violation was a sporting infraction as Art. 5.1 can only be breached by a club, not an association. $^{95}$

3.2.3.1 The Barcelona and Real Madrid cases With regard to the liability of the clubs, the Panel in the Barcelona case and the Sole Arbitrator in the Real Madrid case accepted the clubs' arguments that the registration of minors with the regional associations was valid, although they adopted different legal reasoning. The Panel of the Barcelona case underlined peculiarities of the Spanish governance system in football established under the Spanish law and noted that the Club did not have any discretion with regard to the registration of players with the FCF in order for them to participate in the regional competitions. The Club was obliged to follow the registration procedure to comply with the requirements of the Spanish law. ${ }^{96}$ The exclusive authority given to the regional associations to organise competitions within their territories meant that Barcelona could not go directly to the RFEF to register the minors. Therefore, according to the Panel, the Club was prevented from acting in accordance with the registration requirement of the RSTP, i.e. registering the minors with the RFEF, and had not breached Art. 5.1.97

The Sole Arbitrator of the Real Madrid case also considered the mandatory nature of the registration of the Club's minors with the FFM for the regional competitions due to the exclusive competency enjoyed by the FFM under Spanish law. ${ }^{98}$ However, unlike the FCF, the FFM had immediately notified the RFEF about the registration

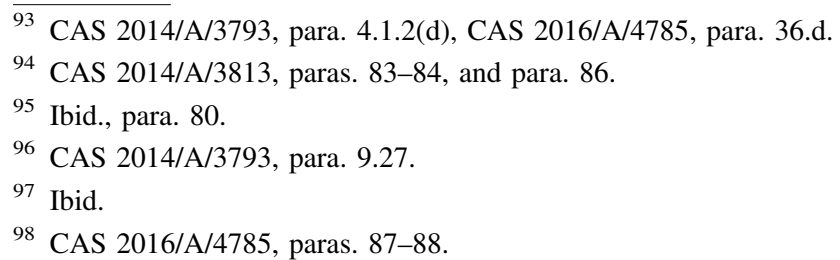


of the minors by Real Madrid. ${ }^{99}$ According to the Sole Arbitrator, Art. 5 of the RSTP does not specify in what manner a registration must occur, and therefore, the communications made by the FFM to the RFEF concerning the minors were considered as an effective way of registration for the purposes of the RSTP. Therefore, the Sole Arbitrator cleared Real Madrid from any wrongdoings with regard to Art. 5.1 of the RSTP. ${ }^{100}$

What is also important to underline at this stage that the rulings concerning the breach Art. 5.1. of the RSTP by the Clubs had different impacts on the reduction of sanctions before the CAS. While the Panel of the Barcelona case did not modify the sanctions of Barcelona at all, the Sole Arbitrator decided to lower the sanctions of Real Madrid. ${ }^{101}$ This was once again due to different legal reasoning followed in each case. The Panel of the Barcelona case examined the proportionality of sanctions for the infractions committed whereas the Sole Arbitrator of the Real Madrid case assessed the appropriate sanctions for the Club's regulatory breaches. ${ }^{102}$ For the Panel of the Barcelona case, the proportionality of sanctions against the Club was needed to be analysed against certain benchmarks; the power to dissuade the Club from repeating violations again in the future and the importance of the rule that is being protected. Accordingly, the Panel considered the sanctions against the Club proportionate to deter not only Barcelona but also other clubs from potential breaches of the regulatory regime which is important for the protection of minors in football. ${ }^{103}$ In contrast, in analysing the appropriateness of sanctions, the Sole Arbitrator of the Real Madrid case underlined the importance of taking into account 'all relevant factors in the case and the degree of the offender's guilt' in accordance with the FIFA Disciplinary Code. ${ }^{104}$ This approach meant that each offence that committed by the Club was taken into consideration to determine the appropriate sanction. In this connection, the Sole Arbitrator acknowledged that Real Madrid committed less infractions than Barcelona and what it had been ruled by the FIFA judicial bodies in their decision. ${ }^{105}$ Therefore, the sanctions of Real Madrid were reduced to reflect the level of violations by the Club.

3.2.3.2 The RFEF case Regarding the liability of the RFEF, nevertheless, the Panel of the RFEF case did not

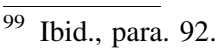

100 Ibid., para. 93.

101 CAS 2014/A/3793, para. 9.36, CAS 2016/A/4785, para. 108.

102 CAS 2014/A/3793, paras. 9.32-9.34, CAS 2016/A/4785, para. 105.

103 CAS 2014/A/3793, para. 9.34.

104 CAS 2016/A/4785, para. 105.

105 Ibid., para. 107.
}

accept the arguments put forward by the Spanish national governing body. Firstly, the Panel noted that Art. 5 of the RSTP entails certain duties not only on the part of clubs but also on associations. ${ }^{106}$ While clubs are obliged to start the registration process of a player by petitioning their associations, the duty of associations does not end if there is no petition by clubs. The RFEF actually had a duty to ensure the compliance of its clubs with the RSTP and the Panel considered that the breach of this duty underpins the breach of Art. 5 by national associations. Thus, the breach of Art. 5.1 cannot only be committed by clubs, i.e. it is not a sporting infraction. ${ }^{107}$ In addition, the Panel also ruled that the RFEF cannot claim a lack of jurisdiction on its regional associations to oversee the implementation of Art. 5.1 of the RSTP because of the exclusive authority given to the FCF under the Spanish law. The RFEF, as a FIFA member, is expected to fully comply with the FIFA regulations under which it is required to ensure their affiliated members also comply with the rules and regulations of FIFA. ${ }^{108}$ For all these reasons, the Panel held the RFEF liable for the violations of Art 5.1 in all 31 minors.

\subsubsection{The distinction between registering and reporting minors in the academies as per Art. 19bis of the RSTP and the registration of minors with associations}

The Panel of the Barcelona case and the Sole Arbitrator of the Real Madrid case examined the violations by the clubs concerning the registration and reporting requirements for minors in their academies. The main legal question was whether the registration of minors with the FCF and FFM was actually sufficient for the clubs to comply with Art. 19bis of the RSTP. Both clubs argued that the minors in their respective academies, La Masia of Barcelona and the Cantera of Real Madrid, were actually reported when they were registered with the regional associations. Moreover, Real Madrid claimed that Art. 19bis does not specify any particular method of reporting, and therefore, the registration of the minors with the FFM should suffice in complying with the obligations of this specific provision. ${ }^{109}$ In other words, according to the clubs, the registrations with the regional associations were deemed to be fulfilling the reporting requirement too for the purposes of the RSTP.

The Panel in the Barcelona case rejected the Club's arguments. ${ }^{110}$ According to the Panel, the obligation of reporting imposed under Art. 19bis of the RSTP is actually a further, and different, obligation than the one concerning

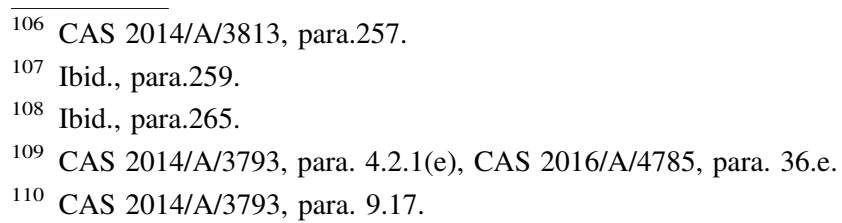


the registration of the players in Art.5. This distinction derives from the rationale behind Art. 19bis which is about protecting minors who are not always registered with a club, but still train and play in the academy. The Panel noted that minors move from one country to another and join academies without actually registering with associations. In these circumstances, it is highly likely that minors attending academies are no longer living with their families and, therefore, might require a further attention. The registration and reporting obligation under Art. 19bis of the RSTP aim to gather information about attendance in academies regardless of whether minors have been registered with the relevant association or not, so that the protection of the framework is extended. ${ }^{111}$ Therefore, the Panel held that Barcelona breached Art. 19bis by not reporting any of the minors in question and the registrations with the FCF were not sufficient to satisfy the reporting requirements. ${ }^{112}$ The same legal reasoning was also used by the Sole Arbitrator who ruled the violation of the provision by Real Madrid. $^{113}$

\section{Conclusion}

This paper has sought to synthesize legal reasoning of the CAS in three Spanish cases with a view to drawing some conclusions for the practical operation of the regulatory framework for the protection of minors under the RSTP. To sum up, there are four important lessons that can be drawn from the analysis of the Sect. 3.2 above.

(a) National associations have an oversight responsibility to ensure their members comply with the regulations of FIFA which also includes the provisions of the RSTP concerning the protection of minors. As a result, the regulatory violations by the clubs at a national level creates the basis for liability for a national association because of the national association's status as a FIFA member and the corresponding legal duty that arises. For this reason, national associations must ensure that their members adhere to the regulatory framework under the RSTP. Otherwise, national associations cannot escape from liability.

(b) The regulatory framework under the RSTP is applicable to all minors. The confusion about the applicability of the framework to minors at the certain age category, now U-10s, is addressed in all three cases and now rectified by FIFA in its Circular

\footnotetext{
111 Ibid.

112 Ibid., para. 9.18.

113 CAS 2016/A/4785, para. 102.
}

no. 1468. The key distinction for the practical operation of the system is that national associations must verify the international transfer or the first registration of a minor even if the player is under the age of 10 years and neither ITC nor the approval of the Sub-Committee are required. For any player over the age of 10, an application for the approval of the Sub-Committee must be made through following the right procedure as prescribed under Art. 19.4 and Annexes 2 and 3 of the RSTP and one of the exceptions of Art. 19.2 of RSTP must be met.

(c) National associations are under the duty to ensure that minors are registered with them rather than any regional associations within their territories. For the purposes of the RSTP, an 'association' means national associations not regional associations. In addition, if clubs want to avoid liability under the framework, they must also ensure the registration of their minors with national associations.

(d) The registration of minors with national associations does not automatically satisfy the reporting and registration requirements of Art. 19bis of the RSTP. Clubs must register and report minors at their academies with their respective national associations to comply with the requirements of Art. 19bis as the rationale behind this obligation differs from the registration requirement under Art. 5.

These findings of the CAS are important for the application of the framework at the national level. These important lessons must be closely observed and complied by both clubs and national associations if they want to be in compliance with the RSTP and to offer a greater protection for minors in football.

Open Access This article is distributed under the terms of the Creative Commons Attribution 4.0 International License (http://creative commons.org/licenses/by/4.0/), which permits unrestricted use, distribution, and reproduction in any medium, provided you give appropriate credit to the original author(s) and the source, provide a link to the Creative Commons license, and indicate if changes were made.

\section{References}

Brackenridge C, Pitchford A, Russell K, Nutt G (2006) Child welfare in football: an exploration of children's welfare in the modern game. Routledge, London

Darby P, Akindes G, Kirwin M (2007) Football academies and the migration of African football labour to Europe. J Sport Social Issues 31(2):143-161. https://doi.org/10.1177/019372350730 0481

Derung V (2015) Protecting underage football players in the transfer system. World Sports Law Report, September 2015

Donnelly P, Petherick L (2004) Workers' playtime? Child labour at the extremes of the sporting spectrum. Sport in Society 7(3):301-321. https://doi.org/10.1080/1743043042000291659 
Eliasson I (2017) The gap between formalised children's rights and children's real lives in sport. Int Rev Sociol Sport 52(4):470-496. https://doi.org/10.1177/1012690215608516

Esson J (2015a) You have to try your luck: male Ghanaian youth and the uncertainty of football migration. Environ Plan A Econ Space 47(6):1383-1397. https://doi.org/10.1177/0308518X1559 4920

Esson J (2015b) Better off at home? Rethinking responses to trafficked West African footballers in Europe. J Ethnic Migr Stud 41(3):512-530. https://doi.org/10.1080/1369183X.2014. 927733
Lembo C (2011) FIFA transfers regulations and UEFA player eligibility rules: major changes in European football and the negative effect on minors. Emory Intern Law Rev 25:539-585

Rowe M (2016) The beautiful game? Geographical 88(11):33-39

Stafford A, Alexander K, Fry D (2015) 'There was something that wasn't right because that was the only place I ever got treated like that': children and young people's experiences of emotional harm in sport. Childhood 22(1):121-137. https://doi.org/10. $1177 / 0907568213505625$ 